\title{
PASSING ON
}

\author{
Juliet Fraser
}

In this last editorial, Bob writes about the shifting ground of history, the inconstant tension between time and the individual. How do we deal with the great tide of culture? How do we come to terms with the enormity of the back catalogue? How do we leave our mark?

My dear friend and Editor of this journal, Bob Gilmore, died on 2 January 2015. He had been diagnosed with cancer in September 2012; it is characteristic that he should jump at the chance to take on the TEMPO Editorship with that diagnosis ringing in his ears - Bob left his mark all over the place by getting on and doing, and with good cheer. Characteristic too, perhaps, that many even of his close friends were unaware of how ill he was towards the end of 2014. He was full of plans, abounding in time for others, indomitable.

Shortly after Bob died, I found myself writing of him to a friend that 'If the world were full of people like him, it would be a much better place; if the new music world were full of people like him, it would be thriving and unstoppable!'

To be honest, I'm not always sure what new music is. Bob and I grappled with the terminology when we took on the journal, settling on 'new music' because it seemed the most open label but acknowledging the limitations perhaps of any term to capture a genre we could feel but not really describe without getting bored of our own words. I suppose we tend to know what we think is or isn't new music, and maybe that's good enough. Also, of course, it's good that we don't all agree. Bob always followed his nose, and encouraged others to do the same: I had the impression that feeling something for a piece of music far surpassed a rational categorisation or dry evaluation in his eyes.

In the same way, I'm not always sure what it is to be part of the new music community. What is this territory that we share? Bob referred to this in his first editorial in which he defended the merits of a good ol' fashioned printed journal in this age of fast-moving, everybody-shout-about-it-now careerism. Musicologically speaking, we may be past the era of 'schools', but I hope we haven't moved into an era of 'niches' in which, anxious at the pluralism around us, we seek to carve our own niche, huddling in our own shallow recess which blinkers us to the broader horizon and prevents us from offering a broader embrace. As a performer I suppose I have a freer passage through our camps and tribes than some others; belonging comes from participating, I feel, and the marks I leave must be more numerous, varied and ephemeral than, say, those of a composer or biographer (I remember Bob deliberating over who should be the subject of his next biography).

When writing the new Guidelines for this journal together, Bob and I were excited to discover that we had complete agreement concerning our aims, and proclaimed in passionate unison that 'TEMPO exists to document the international new music scene while contributing to, and stimulating, current debates therein'. Reflecting on this, 
and in answer to the many of you asking 'what is the future of TEMPO?', I reaffirm that our vision is to serve and inspire our community, to try in some small way to celebrate the plurality and strengthen the collectivism.

Bob elevated people: to spend time with Bob was to receive a subthe shot of optimism about one's creative endeavours. Yet this was never done by figuring out what one's place was, one's niche, or by boxing things up or in; the horizons were infinite and there was space enough for all. If we are interested in shaping the future of new music, in celebrating the tentative affinities between us, how about we propagate the Gilmore meme?

I've thrown down a gauntlet to myself: to be more Bob-like. Because I like achievable goals and probably wouldn't suit a ginger 'fro, I am focusing on channelling his generosity and his optimism. Like this, his legacy lives on in more than biography, review, friendship or memory. Bob made our individual 'grounds' - our musical horizons - shift, and all for the better since he encouraged us towards breadth, towards open ears and open attitudes, towards seeking, and expecting, the joy in music. 